\title{
2014 Award for Distinguished Public Service
}

Philip Kutzko received the 2014 Award for Distinguished Public Service at the 120th Annual Meeting of the AMS in Baltimore, Maryland, in January 2014.

\section{Citation}

The American Mathematical Society's 2014 Award for Distinguished Public Service is presented to Phil Kutzko for his leadership of a national effort to increase the number of doctoral degrees in the mathematical sciences earned by students from underrepresented groups. Kutzko was one of several faculty at the Department of Mathematics at the University of Iowa who undertook, in 1995, to increase minority representation in its graduate program. In this role he has served as director of the department's Sloan Foundation Minority Scholarship Program. As a result of this departmental effort, more than twenty-five U.S. citizens of minority backgrounds have earned Ph.D.s in mathematics at the University of Iowa in the period 2001-2013. Kutzko, together with colleagues in the mathematics and statistics departments at the three Iowa Regents universities, founded the National Alliance for Doctoral Studies in the Mathematical Sciences; Kutzko has written the proposals to NSF through which the Alliance is funded and has served as its director from its inception. The Alliance, founded in 2002, has grown to be a community of more than 250 faculty nationally who work closely with math science majors from minority backgrounds together with faculty at twenty-six doctoral granting departments in the mathematical sciences.

Kutzko's area of research is representation theory of $p$-adic groups with applications to the local Langlands program. He has continued to maintain his research program throughout his many years working on behalf of Ph.D. students from underrepresented backgrounds. Indeed, three of his advisees, all of them from minority backgrounds, received their Ph.D.s under his direction in 2012. He is a most worthy recipient of the Distinguished Public Service Award.

DOI: http://dx.doi.org/10.1090/noti1115

\section{Biographical Sketch}

Phil Kutzko was born and raised in New York City. He is a product of the New York City public schools, and he attended the City College of New York. He received his M.S. and Ph.D. degrees at the University of Wisconsin. He joined the University of Iowa mathematics faculty in 1974. Kutzko's research area is the representation theory of $p$-adic groups with applications to number theory. He is the author, with Colin Bushnell, of a monograph in the Annals of Mathematics Studies and

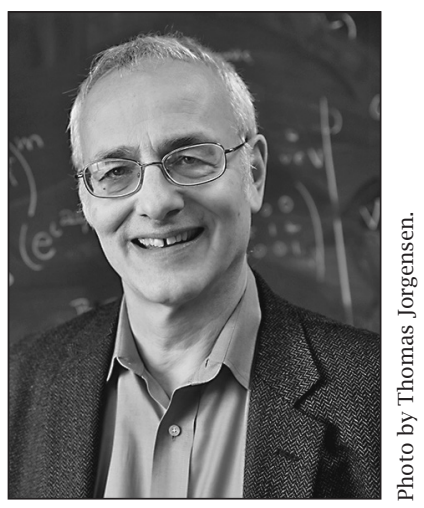

Philip Kutzko was an invited section speaker at the International Congress of Mathematicians in Berkeley in 1986. He is presently a University of Iowa Collegiate Fellow and a Fellow of the American Association for the Advancement of Science.

Kutzko is honored to have played a part in the University of Iowa Department of Mathematics' activities in minority graduate education and in the extension of these activities to other departments of mathematical sciences, including those of the three Iowa Regents universities. In this context, he directs the departmental Sloan Foundation Minority Ph.D. Program as well as the National Alliance for Doctoral Studies in the Mathematical Sciences, an NSF-funded project that involves mathematical sciences departments at a variety of colleges and universities and whose goal is to increase the number of doctoral degrees in the mathematical sciences awarded to students from backgrounds that are underrepresented in these fields. Kutzko was honored for his work in this area with the 2008 Presidential Award for Excellence in Science, Mathematics and Engineering Mentoring. This award was presented to him by President Obama in a White House ceremony in January 2010.

\section{Response from Philip Kutzko}

I am deeply honored to receive the 2014 Award for Distinguished Public Service from the American Mathematical Society and doubly honored when I reflect on those who have preceded me in this 


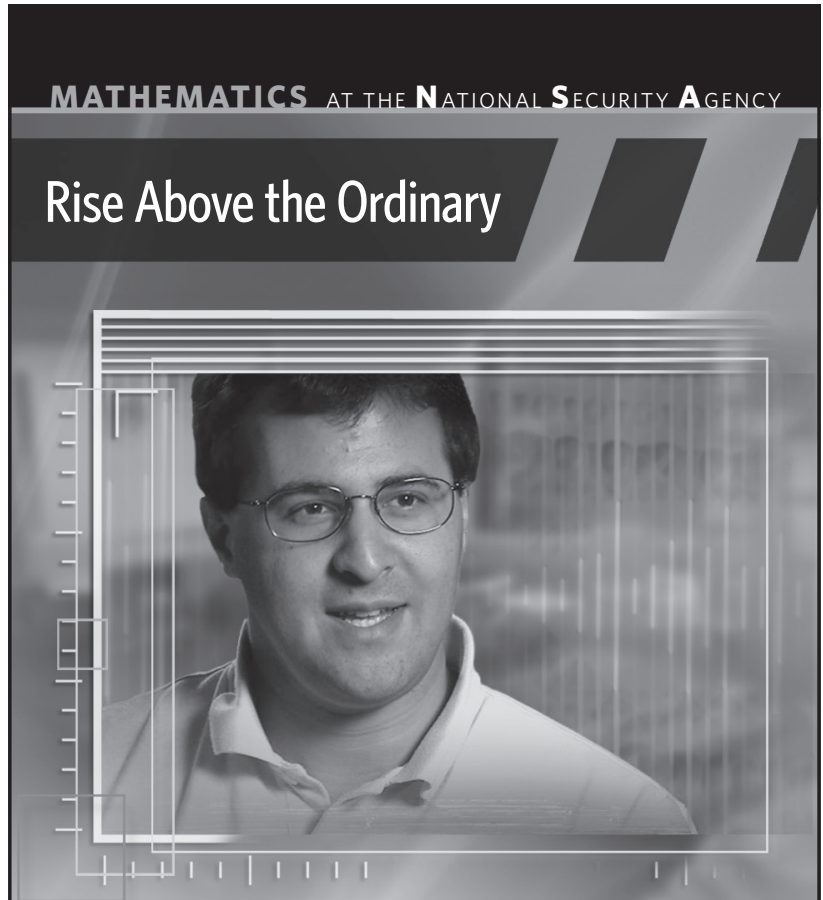

A career at NSA is no ordinary job. It's a profession dedicated to identifying and defending against threats to our nation. It's a dynamic career filled with challenging and highly rewarding work that you can't do anywhere else but NSA.

You, too, can rise above the ordinary. Whether it's producing valuable foreign intelligence or preventing foreign adversaries from accessing sensitive or classified national security information, you can help protect the nation by putting your intelligence to work.

NSA offers a variety of career fields, paid internships, co-op and scholarship opportunities.

Learn more about NSA and how your career can make a difference for us all.

\section{KNOWINGMATTERS}

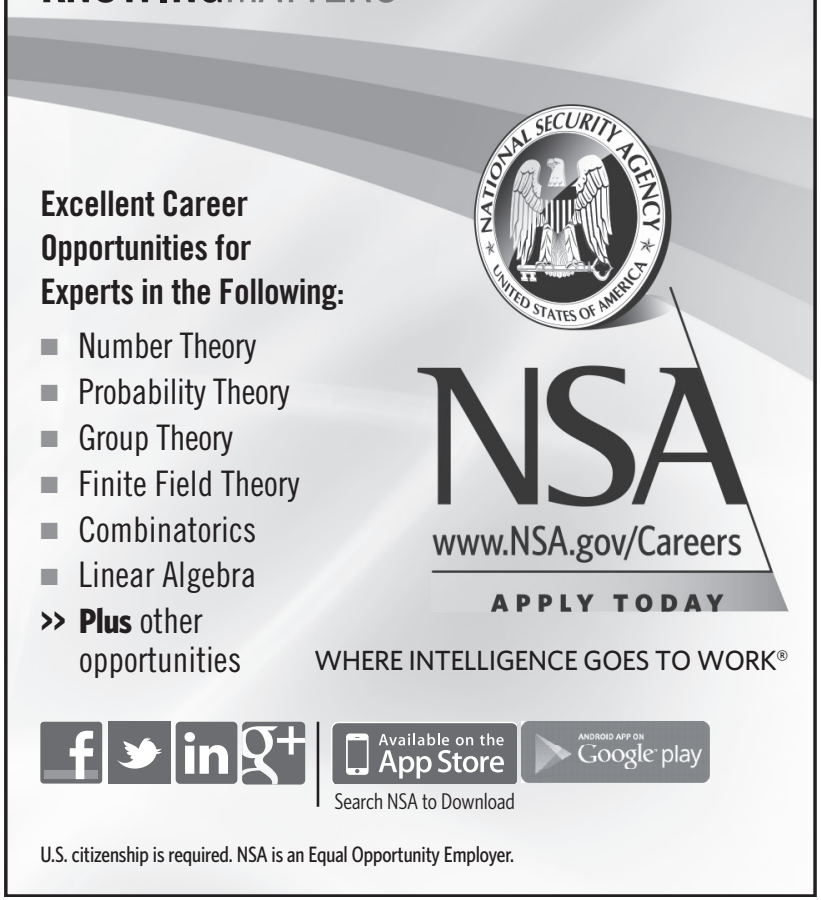

honor. Our initial effort to build diversity into the core of our graduate program at the University of Iowa was greatly aided by the support, and wisdom, of Carlos Castillo Chavez, the 2010 recipient of this award. It is hard to imagine that our department-or our National Alliance-would have had the success that it has had without his advice and leadership. The work that my colleagues and I have done on types and covers for $p$-adic groups has its origin in the ideas of Roger Howe, the 2006 recipient of this award; it builds on the pioneering work he did in this area. Paul Sally, the 2000 recipient of this award, has provided a whole generation of mathematicians with a model we may emulate-a model for research, a model for mentoring, and, above all, a model for citizenship. My personal and professional debt to him is enormous, and it is a pleasure to acknowledge it on this occasion.

This is a critical time for our profession. It is the nature of the way in which we do mathematics that it is in constant need of renewal, of new ideas and new approaches-of new eyes. This fresh perspective will come, as it always has in the past, from the inclusion of groups that have been previously underrepresented in our profession if we will only open the door and welcome them as they take their place among us. This door was opened for me by my high school and college teachers in New York City, by my professors at the University of Wisconsin, and by the mathematicians in whose steps I follow in accepting this high honor. I am deeply grateful for this recognition of the work that my colleagues and I are doing to open these doors for others.

\section{About the Award}

The Award for Distinguished Public Service is presented every two years to a research mathematician who has made a distinguished contribution to the mathematics profession during the preceding five years. The purpose of the award is to encourage and recognize those individuals who contribute their time to public service activities in support of mathematics. The award carries a cash prize of US $\$ 4,000$.

The Award for Distinguished Public Service is made by the AMS Council, acting on the recommendation of the selection committee. For the 2014 award, the members of the selection committee were Richard A. Askey, C. Herbert Clemens, Roger E. Howe, William McCallum, and Sylvia M. Wiegand.

Previous recipients of the award are Kenneth M. Hoffman (1990), Harvey B. Keynes (1992), I. M. Singer (1993), D. J. Lewis (1995), Kenneth C. Millett (1998), Paul J. Sally Jr. (2000), Margaret H. Wright (2002), Richard Tapia (2004), Roger Howe (2006), C. Herbert Clemens (2008), Carlos Castillo-Chavez (2010), and William McCallum (2012).

-Elaine Kehoe 